\title{
The metabolic syndrome is associated with complicated gallstone disease
}

\author{
Naim Ata MD1, Metin Kucukazman MD¹, Bunyamin Yavuz MD², Hakan Bulus MD², Kursat Dal MD²,

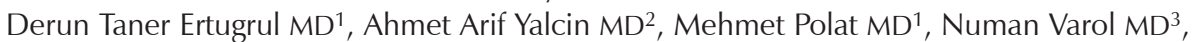

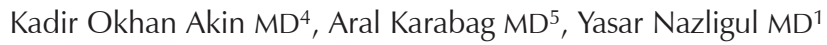

N Ata, M Kucukazman, B Yavuz, et al. The metabolic syndrome is associated with complicated gallstone disease. Can J Gastroenterol 2010;25(5):274-276.

BACKGROUND: Gallstone disease (GD) is a common condition worldwide. Several studies demonstrated that the presence of gallstones is strongly associated with cardiovascular disease. The metabolic syndrome is a highly prevalent cardiovascular condition.

OBJECTIVE: To examine the relationship between complicated GD (CGD) and the metabolic syndrome or its components.

METHODS: Two hundred seventeen patients with gallstones were examined. All patients underwent biliary ultrasonography after a complete medical history and laboratory examination. Data collection for the diagnosis of metabolic syndrome included measurements of waist circumference, blood pressure and lipids, and biochemical tests.

RESULTS: Of the 217 patients examined, 115 patients (53\%) had CGD and 102 patients (47\%) had uncomplicated GD (UCGD). There was a significant difference between the number of patients with large gallstones in the CGD and UCGD groups $(n=14$ [12\%] versus $n=2[2 \%]$, respectively; $\mathrm{P}=0.004)$. Metabolic syndrome, diabetes mellitus and large waist circumference were more prevalent in the CGD group than in the UCGD group. Homeostatic model assessment of insulin resistance scores were higher in the CGD group than in UCGD group (2.51 [95\% CI 0.57 to 23.90] versus 2.20 [95\% CI 0.09 to 8.87], respectively; $\mathrm{P}=0.032$ ). Logistic regression analysis revealed that the presence of metabolic syndrome (OR $1.434 ; 95 \%$ CI 1.222 to 1.846, $\mathrm{P}=0.014$ ), diabetes mellitus ( $\mathrm{OR} 1.493 ; 95 \% \mathrm{CI} 1.255$ to 1.953 ; $\mathrm{P}=0.035$ ) and large gallstones (OR $1.153 ; 95 \%$ CI 1.033 to 1.714 ; $\mathrm{P}=0.017$ ) were independent predictors of CGD.

CONCLUSION: Results of the present study demonstrated that metabolic syndrome, diabetes and gallstone size were associated with CGD. Further prospective studies are needed to understand the clinical importance of this association.

Key Words: Cholelithiasis; Gallstone disease; HOMA IR; Metabolic syndrome

Gallstone disease (GD) is a common condition worldwide. Jecause of its high prevalence and elevated health costs, it is an important condition for which further research is needed. Cholesterol comprises more than $80 \%$ of gallstones, which are associated with older age, pregnancy, obesity, insulin resistance, specific dietary habits, genetic background and ethnicity (1-3).

The pathogenesis of gallstones is multifactorial and involves environmental and individual factors resulting in three main consequences: bile cholesterol saturation, cholesterol nucleation and gallbladder dysmotility (4). Several studies demonstrated that gallstones are strongly associated with cardiovascular disease (5).

Metabolic syndrome is a highly prevalent cardiovascular condition. The 2001 National Cholesterol Education Program Adult Treatment Panel III report (6) provided a working definition of the metabolic syndrome on the basis of the presence of three to

\section{Le syndrome métabolique s'associe à une lithiase biliaire compliquée}

HISTORIQUE : La lithiase biliaire (LB) est un trouble courant de par le monde. Plusieurs études démontrent que la présence de calculs biliaires s'associe fortement à une maladie cardiovasculaire. Le syndrome métabolique est un trouble cardiovasculaire hautement prévalent.

OBJECTIF : Examiner le lien entre une LB compliquée (LBC) et le syndrome métabolique ou ses éléments.

MÉTHODOLOGIE : Deux cent dix-sept patients ayant des calculs biliaires ont été examinés. Ils ont tous subi une échographie biliaire après l'obtention d'antécédents complets et un examen de laboratoire. La collecte de données pour diagnostiquer le syndrome métabolique incluait les mesures du tour de taille, de la tension artérielle, de la lipidémie ainsi que des tests biochimiques.

RÉSULTATS : Des 217 patients examinés, 115 (53\%) avaient une LBC et 102 (47\%), une LB non compliquée (LBNC). Les chercheurs ont constaté une différence importante entre le nombre de patients ayant de gros calculs des groupes ayant une LBC par rapport à ceux ayant une LBNC $(n=14$ [12\%] comparativement à $n=2$ [2\%], respectivement; $\mathrm{P}=0,004)$. Le syndrome métabolique, le diabète et un gros tour de taille étaient plus prévalents dans le groupe ayant une LBC que dans celui ayant une LBNC. L'évaluation par modèle homéostatique des indices d'insulinorésistance était plus élevée dans le groupe ayant une LBC que dans celui ayant une LBNC $(2,51$ [95 \% IC 0,57 à 23,90] par rapport à 2,20 [95 \% IC 0,09 à 8,87], respectivement; $\mathrm{P}=0,032$ ). L'analyse de régression logistique a révélé que le syndrome métabolique (RRR 1,434; 95 \% IC 1,222 à 1,846, P=0,014), le diabète (RRR 1,493; 95 \% IC 1,255 à 1,$953 ; \mathrm{P}=0,035$ ) et de gros calculs (RRR 1,153; $95 \%$ IC 1,033 à 1,$714 ; \mathrm{P}=0,017$ ) étaient des prédicteurs indépendants de LBC. CONCLUSION : Les résultats de la présente étude démontrent que le syndrome métabolique, le diabète et la dimension des calculs biliaires s'associent à une LBC. D'autres études prospectives s'imposent pour comprendre l'importance clinique de cette association.

five quantitatively defined markers: abdominal obesity, high blood pressure, high fasting glucose level, high triglyceride levels and reduced levels of high-density lipoprotein cholesterol (HDL-C) (6). It is known that the metabolic syndrome and diabetes are risk factors for GD (7); however, there are no data regarding the association between complicated GD (CGD) and metabolic syndrome or its components.

The aim of the present study was to examine the relationship between CGD and the metabolic syndrome or its components.

\section{METHODS}

One hundred two consecutive patients with uncomplicated GD (UCGD) and 115 consecutive patients with CGD were examined in the internal medicine and surgery clinics, and emergency room of the Kecioren Teaching and Research Hospital (Ankara, Turkey). Patients were recruited between January 2008 and April 2009. All subjects

${ }^{1}$ Department of Internal Medicine; ${ }^{2}$ Department of Cardiology; ${ }^{3}$ Department of Surgery; ${ }^{4}$ Department of Biochemistry; ${ }^{5}$ Department of Radiology,

Kecioren Teaching and Research Hospital, Ankara, Turkey

Correspondence: Dr Bunyamin Yavuz, Department of Cardiology, Kecioren Teaching and Research Hospital, Cinnah Caddesi No:11/6,

Kecioren-Ankara 06680, Turkey. Telephone 90-312-427-3108, fax 90-312-356-9003, e-mail byavuz@gmail.com

Received for publication May 13, 2010. Accepted July 13, 2010 
underwent biliary ultrasonography after a complete medical history and laboratory examination. Patients who experienced at least one acute cholecystitis attack were defined as having CGD. Data collection included the exploration for risk factors for coronary artery disease, waist circumference measurement (measured at the level of umbilicus with the patient standing), blood pressure measurement, biochemical tests, lipid measurements, life-style habits and medications. Patients receiving statins or fibrates before lipid measurement were excluded because of the possibilty of introducing bias in the determination of metabolic syndrome.

Informed consent was obtained from the study subjects before enrollment; the study protocol was approved by the ethics committee of the Kecioren Teaching and Research Hospital.

\section{Diagnosis of metabolic syndrome}

Participants were defined as having the metabolic syndrome if they fulfilled three or more of the following criteria: waist circumference greater than $102 \mathrm{~cm}$ for men, greater than $88 \mathrm{~cm}$ for women; diagnosed with hypertension or receiving antihypertensive medication, or two blood pressure measurements exceeding 130/85 mmHg; diagnosed with diabetes mellitus or receiving antidiabetic treatment, or a fasting blood glucose level of greater than $6.105 \mathrm{mmol} / \mathrm{L}$; HDL-C level lower than $1.036 \mathrm{mmol} / \mathrm{L}$ for men, lower then $1.295 \mathrm{mmol} / \mathrm{L}$ for women; and triglyceride levels above $1.695 \mathrm{mmol} / \mathrm{L}$.

\section{Biliary ultrasonography}

Patients underwent real-time ultrasonographic studies after an overnight fast. Gallstones were defined by the presence of strong intraluminal echoes that were gravity dependent or that attenuated ultrasound transmission (acoustic shadowing). At the completion of each patient's participation in the study, all ultrasonographic studies were evaluated again by the same radiologist. A gallstone size of $2.5 \mathrm{~cm}$ or larger was defined as large, whereas a gallstone size smaller than $2.5 \mathrm{~cm}$ was defined as small.

\section{Biochemical analysis}

Blood samples were drawn from an antecubital vein from participants after they had fasted for more than $12 \mathrm{~h}$. Total cholesterol and triglyceride levels were measured with commercially available enzymatic colorimetric tests (Konelab, Finland). Low-density lipoprotein cholesterol and HDL-C levels were also measured with commercially available homogeneous enzymatic colorimetric tests (Konelab, Finland).

Fasting serum glucose concentrations were measured enzymatically with an automatic chemistry analyzer (Konelab 60i, Thermo Scientific, Finland). Fasting serum insulin and C-peptide levels were measured using an immunoluminometric assay (Liaison, DiaSorin, USA). Homeostasis model assessment - insulin resistance (HOMA-IR) was calculated using the updated model available from the Oxford Centre for Endocrinology and Diabetes (8).

\section{Statistical analysis}

Distribution of the continuous variables was determined by the Kolmogorov-Smirnov test. Data are reported as mean \pm SD for normally distributed continuous variables, median (minimum-maximum) for skewed distributed continuous variables and categorical variables are reported as frequencies. Comparisons of categorical variables were performed using the Pearson $\chi^{2}$ test. Then means of normally distributed continuous variables were compared by ANOVA. Skew distributed continuous variables were compared using the Mann-Whitney U test. Skewed variables were log transformed before performing regression analysis. Multivariate logistic regression analyses using a backward procedure on the basis of likelihood ratios were conducted to determine the independent risk factors for CGD. The criteria for variable removal and entry were established at $P \leq 0.10$. The $O R$ with 95\% CI was estimated. SPSS version 10.0 (SPSS Inc, USA) for Windows (Microsoft Corporation, USA) was used for the analysis, with $\mathrm{P}<0.05$ considered to be statistically significant.

\section{RESULTS}

Of 217 patients with gallstones, 115 (53\%) had CGD (mean age $54.6 \pm 10.2$ years) and 102 patients $(47 \%)$ had UCGD (mean age $55.2 \pm 9.6$ years). GD duration ( $13.6 \pm 4.3$ years versus $12.6 \pm 5.3$ years; $\mathrm{P}=0.108)$ and the age at diagnosis of cholelithiasis $(41.0 \pm 9.3$ years versus $42.7 \pm 6.2$ years; $P=0.115$ ) were similar between the $C G D$ and UCGD groups, respectively. There was a significant difference between the number of patients with large gallstones in the CGD and UCGD groups $(n=14[12 \%]$ versus $n=2$ [2\%], respectively; $P=0.004$ ).

The number of patients with metabolic syndrome in the CGD group was significantly higher than in the UCGD group ( $\mathrm{n}=54$ [47\%] versus $n=22$ [22\%], respectively; $\mathrm{P}<0.001$ ). When the components of metabolic syndrome were compared between groups, diabetes mellitus (54 patients [47\%] versus 24 patients [24\%]; $\mathrm{P}<0.001$ ) and large waist circumference (82 patients [71\%] versus 59 patients [58\%]; $\mathrm{P}<0.001$ ) were more prevalent in the CGD group than in the UCGD group, respectively. Low HDL-C (35 patients [30\%] versus 29 patients [28\%]; $\mathrm{P}=0.747$ ) and high triglyceride levels (53 patients [46\%] versus 41 patients [40\%]; $\mathrm{P}=0.382$ ) were not different between the CGD and UCGD groups. Insulin resistance calculated according to the homeostatic model assessment of insulin resitance (HOMA-IR) was higher in the CGD group than in the UCGD group $(2.51$ [95\% CI 0.57 to 23.90] versus 2.20 [95\% CI 0.09 to 8.87]; $\mathrm{P}=0.032$ ). Demographic, clinical and biochemical characteristics of the patients are summarized in Table 1.

The metabolic syndrome and its criteria affecting CGD (diabetes mellitus, high waist circumference), age, HOMA-IR, gallstone size and body mass index were entered into a logistic regression analysis equation to determine the independent factors affecting the CGD patients. Results revealed that the presence of the metabolic syndrome (OR 1.434; 95\% CI 1.222 to $1.846 ; \mathrm{P}=0.014$ ), diabetes mellitus (OR 1.493 ; $95 \%$ CI 1.255 to $1.953 ; \mathrm{P}=0.035)$ and having large gallstones (OR 1.153 ; 95\% CI 1.033 to $1.714 ; \mathrm{P}=0.017$ ) were independent predictors of CGD. Waist circumference, low HDL-C levels, hypertension, high triglyceride levels, HOMA-IR and body mass index were not independently associated with the presence of CGD (Table 2).

\section{DISCUSSION}

In the present study, we found that the presence of metabolic syndrome, diabetes and large gallstones were independent predictors of CGD. The current study is the first to demonstrate metabolic syndrome as an independent risk factor for CGD.

There are several studies $(7,9,10)$ that examined the association between the metabolic syndrome or its components and the prevalence of gallstones. Mendez-Sanchez et al (7) concluded that GD appeared to be strongly associated with metabolic syndrome. Chang et al (9) reported that the prevalence of obesity, abdominal obesity and the metabolic syndrome in subjects with gallstones were higher than in those without. Shaffer (10) reported obesity as a major risk factor for GD (10). Nakeeb et al (11) demonstrated that insulin resistance alone may be responsible for gallbladder dysmotility, which may result in acalculous cholecystitis or gallstone formation. Most of these studies included asymptomatic patients with gallstones or acalculous cholecystitis. CGD and its association with metabolic syndrome was not studied.

Almost $10 \%$ of individuals with asymptomatic cholelithiasis in the general population can be expected to develop symptoms or complications that require treatment within five years (12). Acute cholecystitis, which is acute inflammation of the gallbladder, is a complication that develops in $1 \%$ to $3 \%$ of patients with symptomatic gallstones $(13,14)$. The primary etiology of acute cholecystitis is obstruction of the cystic duct secondary to an impacted gallstone.

There are certain factors that predict a more serious course in patients with asymptomatic gallstones, which warrant a prophylactic cholecystectomy when they are present. These factors include patients with large (larger than $2.5 \mathrm{~cm}$ ) gallstones, patients with congenital hemolytic anemia or nonfunctioning gallbladders, or during bariatric 
TABLE 1

Demographic, clinical and biochemical characteristics of the study subjects

\begin{tabular}{|c|c|c|c|}
\hline & \multicolumn{2}{|c|}{ Gallstone disease } & \multirow[b]{2}{*}{$\mathbf{P}$} \\
\hline & Complicated $(n=115)^{*}$ & Uncomplicated $(n=102)$ & \\
\hline Age, years & $54.6 \pm 10.2$ & $55.2 \pm 9.6$ & 0.621 \\
\hline Sex, female/male (n/n [\%/\%]) & $88 / 27(76 / 24)$ & $71 / 31(70 / 30)$ & 0.251 \\
\hline Gallstone size ${ }^{\dagger}$, large/small, (n [\%]) & $14(12) / 101(88)$ & $2(2 \%) / 100(98)$ & 0.004 \\
\hline Body mass index, $\mathrm{kg} / \mathrm{m}^{2}$ & $30.1 \pm 5.7$ & $31.0 \pm 6.3$ & 0.845 \\
\hline Systolic blood pressure, $\mathrm{mmHg}$ & $130 \pm 11$ & $127 \pm 12$ & 0.563 \\
\hline Diastolic blood pressure, $\mathrm{mmHg}$ & $82 \pm 8$ & $79 \pm 10$ & 0.678 \\
\hline Total cholesterol, mmol/L & $4.921 \pm 0.976$ & $4.990 \pm 1.153$ & 0.631 \\
\hline High-density lipoprotein cholesterol, mmol/L & $1.220 \pm 0.326$ & $1.225 \pm 0.414$ & 0.936 \\
\hline Low-density lipoprotein cholesterol, mmol/L & $3.002 \pm 0.826$ & $3.074 \pm 0.901$ & 0.541 \\
\hline Triglycerides, $\mathrm{mmol} / \mathrm{L}$ & $1.763 \pm 0.415$ & $1.755 \pm 0.359$ & 0.954 \\
\hline
\end{tabular}

Data presented as mean \pm SD unless indicated otherwise. *Patients who experienced at least one acute cholecystitis attack were defined as complicated; ${ }^{\dagger}$ Gallstones measuring $2.5 \mathrm{~cm}$ or larger in size were defined as large; gallstones measuring smaller than $2.5 \mathrm{~cm}$ in size were defined as small

\section{TABLE 2}

Multivariate logistic regression analyses* of complicated gallstone disease as the dependent variable $(n=217)$

\begin{tabular}{lccc}
\hline & Multivariate OR & $95 \% \mathrm{Cl}$ & $\mathbf{P}$ \\
\hline Metabolic syndrome & 1.434 & $1.222-1.846$ & 0.014 \\
Diabetes mellitus & 1.493 & $1.255-1.953$ & 0.035 \\
Large gallstone $^{\dagger}$ & 1.153 & $1.033-1.714$ & 0.017 \\
\hline
\end{tabular}

*Metabolic syndrome, diabetes mellitus, large waist circumference, age and Homeostatic model assessment - insulin resistance, gallstone size and body mass index were entered into the equation for logistic regression analysis. The presence of metabolic syndrome, diabetes mellitus and large gallstones were independent predictors of complicated gallstone disease; ' $G$ allstones measuring $2.5 \mathrm{~cm}$ or larger in size were defined as large

surgery or colectomy (15). There are no data showing that metabolic syndrome causes complications in patients with asymptomatic cholelithiasis, which can be another indication to perform prophylactic surgery.

A human study from Indiana University (Indiana, USA) (16) showed how metabolic syndrome and its criteria can cause CGD. Sixteen nondiseased control patients, 16 patients with chronic acalculous cholecystitis and 16 patients with calculous cholecystitis were matched for sex, body mass index and other metabolic syndrome

\section{REFERENCES}

1. Bennion LJ, Grundy SM. Risk factors for the development of cholelithiasis in man (first of two parts). N Engl J Med 1978;299:1161-7.

2. Bennion LJ, Grundy SM. Risk factors for the development of cholelithiasis in man (second of two parts). N Engl J Med 1978;299:1221-7.

3. Mendez-Sanchez N, Vega H, Uribe M, et al. Risk factors for gallstone disease in Mexicans are similar to those found in Mexican-Americans. Dig Dis Sci 1998;43:935-9.

4. Portincasa P, Moschetta A, Palasciano G. Cholesterol gallstone disease. Lancet 2006;368:230-9.

5. Mendez-Sanchez N, Bahena-Aponte J, Chavez-Tapia NC, et al. Strong association between gallstones and cardiovascular disease. Am J Gastroenterol 2005;100:827-30.

6. Expert Panel on Detection, Evaluation and Treatment of High Blood Cholesterol in Adults. Executive summary of the third report of the National Cholesterol Education Program (NCEP) Expert Panel on Detection, Evaluation, and Treatment of High Blood Cholesterol in Adults (Adult Treatment Panel III).

JAMA 2001;285:2486-97.

7. Mendez-Sanchez N, Chavez-Tapia NC, Motola-Kuba D, et al. Metabolic syndrome as a risk factor for gallstone disease. World J Gastroenterol 2005;11:1653-7. parameters. Both the acalculous and calculous cholecystitis patients had more fat in their gallbladder wall and more cholecystosteatosis than nondiseased control patients.

The same review (16) also reported a recent murine study comparing lean and obese mice fed a low- versus high-carbohydrate diet; results confirmed that obese mice had more fat in the gallbladder. It was also demonstrated that a high-carbohydrate diet exacerbates this phenomenon. In addition, the obese mice and those fed a highcarbohydrate diet had increased gallbladder tissue levels of tumour necrosis factor-alpha, interleukin- 6 and interleukin-1 beta (16). These cytokines have been associated with decreased smooth muscle function and diminished gallbladder absorption. The presence of increased toxic fats and proinflammatory cytokines may result in increased gallbladder pressure and pain. Therefore, high-carbohydrate diets may result in complicating UCGD by causing an increase in inflammatory cytokines. This can be the mechanism underlying the association between the metabolic syndrome and CGD.

\section{CONCLUSION}

Results of the present study demonstrated that the metabolic syndrome, diabetes and gallstone size were associated with CGD. These results suggest that the metabolic syndrome can be regarded as another indication for prophylactic surgery in patients with GD. Further prospective studies are needed to understand the clinical importance of this association.

8. Levy JC, Matthews DR, Hermans MP. Correct homeostasis model assessment (HOMA) evaluation uses the computer program. Diabet Care 1998 21:2191-2.

9. Chang Y, Sung E, Ryu S, Park YW, Jang YM, Park M. Insulin resistance is associated with gallstones even in non-obese, non-diabetic Korean Men. J Korean Med Sci 2008;23:644-50.

10. Shaffer EA. Epidemiology and risk factors for gallstone disease: Has the paradigm changed in the 21st century? Curr Gastroenterol Rep 2005;7:132-40.

11. Nakeeb A, Comuzzie AG, Al-Azzawi H, Sonnenberg GE, Kissebah AH, Pitt HA. Insulin resistance causes human gallbladder dysmotility. J Gastrointest Surg 2006;10:940-8.

12. Halldestam I, Enell EL, Kullman E, Borch K. Development of symptoms and complications in individuals with asymptomatic gallstones. Br J Surg 2004;91:734-8.

13. Indar AA, Beckingham IJ. Acute cholecystitis. BMJ 2002;325:639-43.

14. Friedman GD. Natural history of asymptomatic and symptomatic gallstones. Am J Surg 1993;165:399-404.

15. Schirmer BD, Winters KL, Edlich RF. Cholelithiasis and cholecystitis. J Long Term Eff Med Implants 2005;15:329-38.

16. Pitt HA. Hepato-pancreato-biliary fat: The good, the bad and the ugly. HPB (Oxford) 2007;9:92-7. 


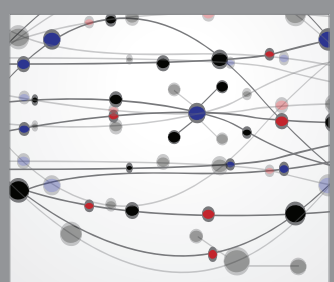

The Scientific World Journal
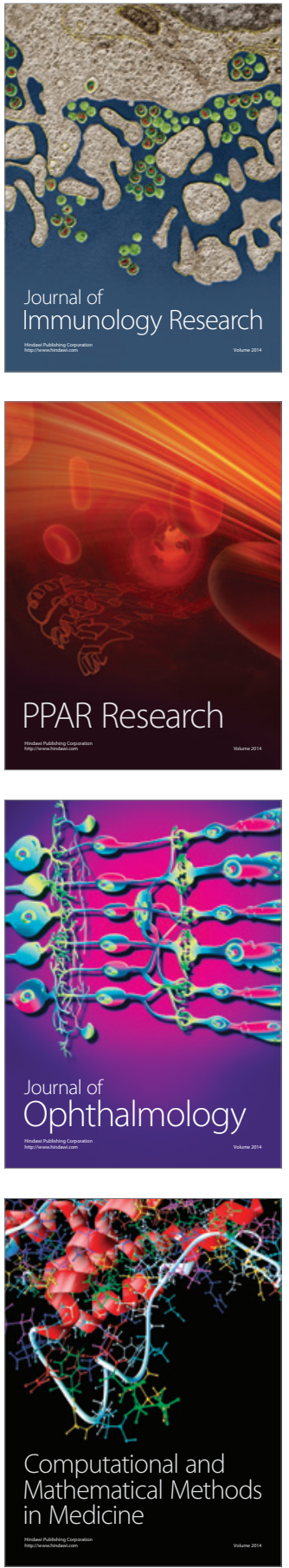

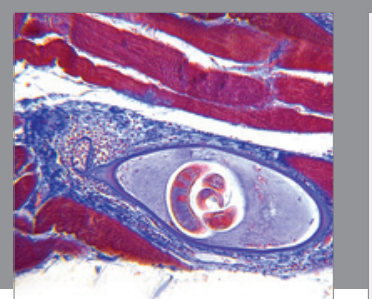

Gastroenterology Research and Practice

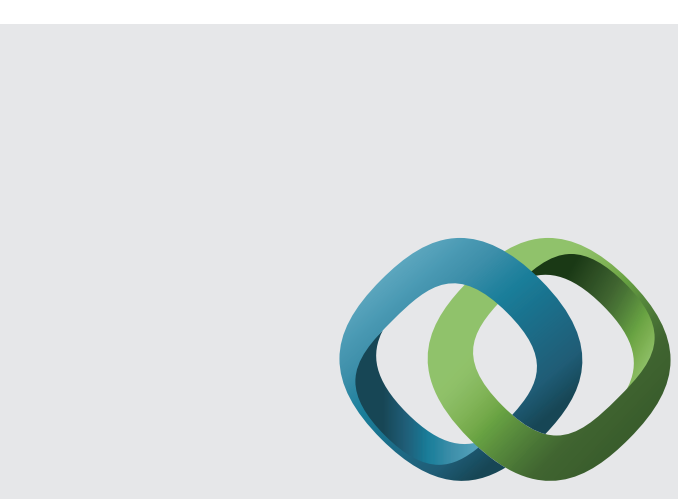

\section{Hindawi}

Submit your manuscripts at

http://www.hindawi.com
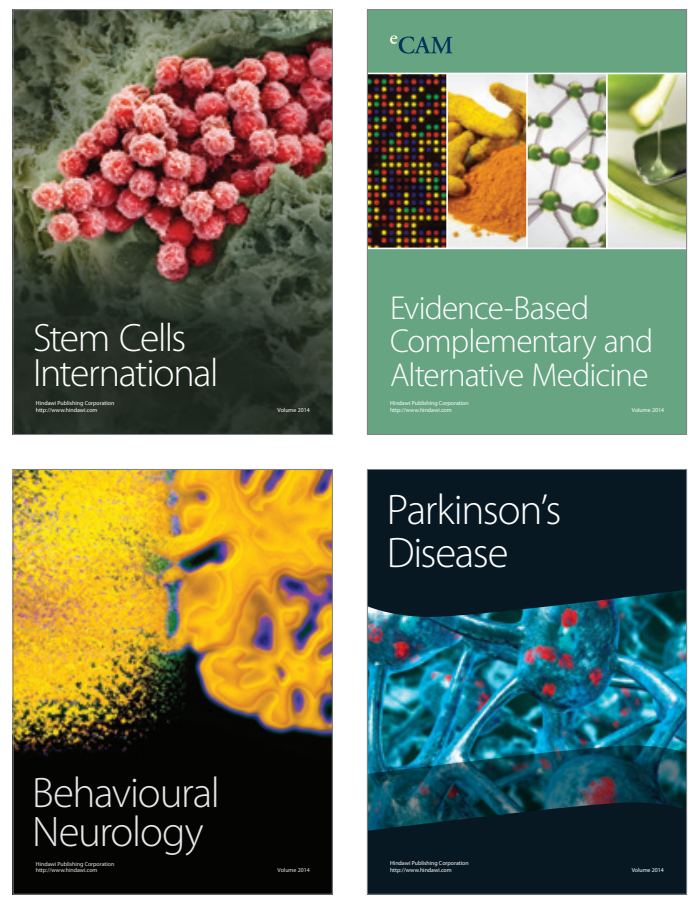
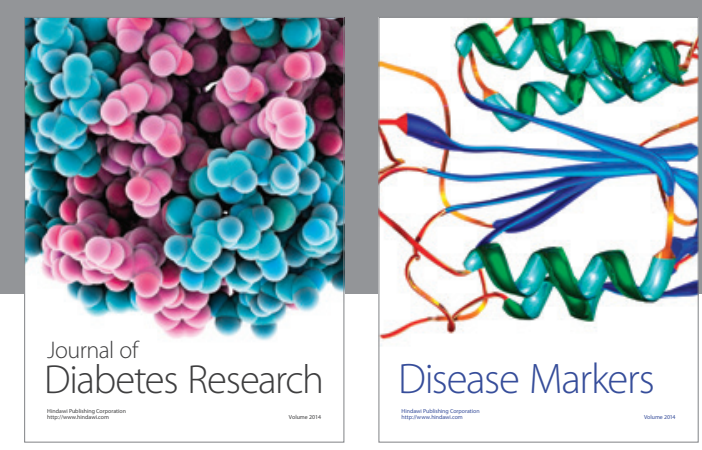

Disease Markers
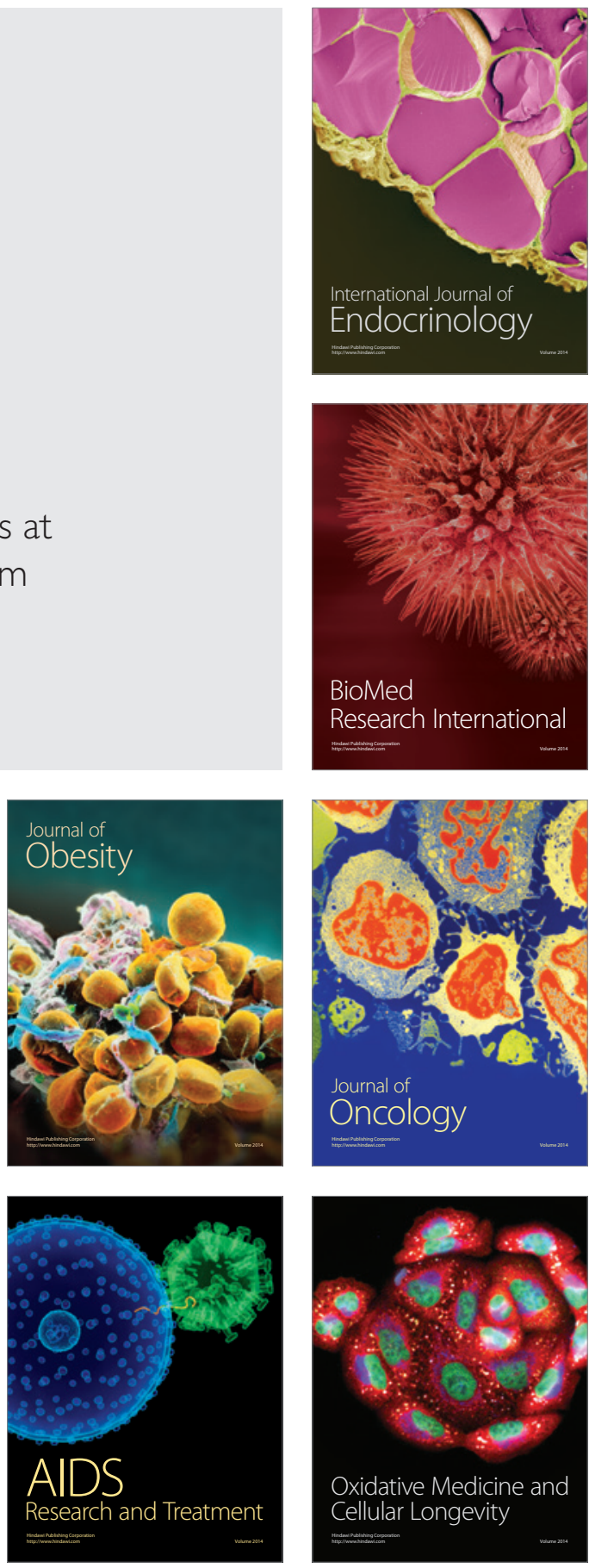